\title{
Carvacrol effect on topotecan cytotoxicity in various human cancer cells in vitro
}

\author{
Hadeel M. Bayoumi ${ }^{1}$, Mayson H. Alkhatib ${ }^{1,2}$, Madeha N. Al-Seeni ${ }^{1}$ \\ 1 Department of Biochemistry, Faculty of Science, King Abdulaziz University, Jeddah, Saudi Arabia \\ 2 Regenerative Medicine Unit, King Fahd Medical Research Center, King Abdulaziz University, Jeddah, Saudi Arabia \\ Corresponding author: Mayson H. Alkhatib (mhalkhatib@kau.edu.sa)
}

Received 12 March 2021 Accepted 9 April 2021 • Published 20 April 2021

Citation: Bayoumi HM, Alkhatib MH, Al-Seeni MN (2021) Carvacrol effect on topotecan cytotoxicity in various human cancer cells in vitro. Pharmacia 68(2): 353-363. https://doi.org/10.3897/pharmacia.68.e65878

\begin{abstract}
Purpose: To investigate the modulatory effect of the natural phytochemical, carvacrol, on Topotecan (TOPO) cytotoxicity and cellular uptake in different cancer cell lines.

Methods: The cytotoxicity of the carvacrol/TOPO combination therapy was determined in vitro using crystal violet assay. Coomassie blue and DAPI fluorescent stains were used for cellular morphology and molecular cell death assessments, respectively. Additionally, TOPO cellular uptake after carvacrol/TOPO combination therapy was determined.

Results: Treatment of HeLa and HCT116 with carvacrol/TOPO resulted in 7.70- and 5.71-fold reduction in TOPO half maximal inhibitory concentration $\left(\mathrm{IC}_{50}\right.$ ), respectively, relative to TOPO single treatment. On the other hand, treatment of MCF-7, HepG2, SKOV3, and $\mathrm{A} 549$ cancer cells with carvacrol/TOPO resulted in increasing the $\mathrm{IC}_{50}$ of TOPO by 1.49-, 1.33-, 1.50- and 1.26-fold, respectively, relative to TOPO single treatment.
\end{abstract}

Conclusion: Carvacrol had enhanced TOPO cytotoxicity and cellular uptake in HeLa and HCT116 cancer cells but might cause TOPO resistance in MCF-7, HepG2, SKOV3 and A549 cells.

\section{Keywords}

Apoptosis, Cellular morphology assessment, Cellular uptake, Combination therapy, Crystal violet assay

\section{Introduction}

In the twenty first century, cancer is still the leading cause of the death in all over the world (Bray et al. 2018). In order to fight cancer, there are three known therapeutic approaches; surgery, irradiation and chemotherapy. Among the previous therapeutic procedures, chemotherapy, used alone or in combination with other forms of therapy is the favorable approach for the treatment of cancer (Rang et al. 2012). Topotecan (TOPO), an inhibitor of the topoisomerase I, the enzyme responsible for DNA replication in cancer cells (O’Dwyer et al. 1994), is the single-agent therapy of choice of many complicated types of cancer (Armstrong et al. 2005). However, like other chemotherapeutic agents, TOPO is associated with dose limiting toxicities such as neutropenia, thrombocytopenia, and anemia, and it has a low chance of being curative if used alone due to the development of topoisomerase I resistance (Bansal et al. 2017). Therefore, there is a need to combine TOPO with a safer agent that has an anticancer effect with a different target in order to enhance TOPO cytotoxicity and at the same time decrease its effective therapeutic dose and thereby its side effects (Wang et al. 2012). 
Scientific studies nowadays are continuing to prove that many natural herbs and plant extracts; that have been used over generations as natural remedies, have phytochemicals (natural constituents), that exert chemoprevention and chemotherapeutic effects (Newman and Cragg 2016). The most important features of those natural ingredients are the safe nature of them relative to chemotherapy and their effectiveness against many diseases which allow them to offer an effective and safer alternative for cancer treatment (Lai and Roy 2004). Carvacrol (2-methyl-5-(1-methylethyl)-phenol), the liquid phytochemical isolated from the essential oil of thyme (thymus vulgaris) and other aromatic plants belonging to the family Lamiaceae, has been used for generations in folk medicine and the previous studies have proven that carvacrol has anti-cancer effects in addition to antioxidant, analgesic, anti-inflammatory, antimicrobial, antiapoptotic, antispasmodic, and antibacterial effects (Fachini-Queiroz et al. 2012; Khan et al. 2018). The strong cytotoxic and proapoptotic effect of carvacrol against various cancer cell lines had been reported in the literature (Sharifi-Rad et al. 2018). Moreover, the Food and Drug Administration (FDA) had assured the non-toxic nature of carvacrol through approving its use as food or chemical flavoring agent (Zotti et al. 2013).

Therefore, the aim of this study is to investigate the effect of carvacrol/TOPO combination treatment on the proliferation of different cancer cell lines relative to TOPO single treatment. Furthermore, assessment of cells morphological alterations and TOPO cellular uptake were performed to have an insight into the possible mechanism of action of this therapy combination.

\section{Materials and methods}

\section{Drugs and chemicals}

Topotecan (TOPO) hydrochloride and carvacrol were purchased from Sigma Aldrich Co. TOPO stock solutions were prepared by dissolving it in distilled water (D.W) and preserved at $-20^{\circ} \mathrm{C}$. Dullbecco's modified eagle's medium (DMEM), fetal bovine serum, trypsin/EDTA, penicillin G/steptomycin antibiotics, 4',6-diamidino-2-phenylindole (DAPI) dihydrochloride solution, dimethyl sulfoxide (DMSO), phosphate buffered saline (PBS) and ethanol were obtained from Beijing Solarbio Science and Technology Co., (Shanghai, China). Crystal violet stain (CV) (from: s.d.fine-CHEM Ltd), Coomassie blue R-250 (CB R-250), sodium dodecyl sulfate (SDS), formaldehyde, acetic acid (AA), and methanol were gifted from King Fahd Medical Research Center (KFMRC).

\section{Cancer cell lines and cell culture}

MCF-7 breast, HeLa cervical, SKOV3 ovarian, HCT116 colon, HepG2 liver, and A549 non-small lung cancer cells were procured from the American Type Tissue Culture Collection (Manassas, VA, USA) and were gifted from the Regenerative Medicine unit at KFMRC.
All cell lines were grown as adherent monolayer cells in a $\left(25 \mathrm{~cm}^{2}\right)$ culture flask and the growth medium (DMEM) was supplemented with $10 \%(\mathrm{v} / \mathrm{v})$ FBS and $1 \%(\mathrm{v} / \mathrm{v})$ penicillin-streptomycin. The cancer cells were incubated in a $5 \% \mathrm{CO}_{2} / 95 \%$ humidified atmosphere at $37^{\circ} \mathrm{C}$. The DMEM was removed from the cell culture flask and changed with new medium every $48 \mathrm{~h}$. Cells were collected by trypsinization and passaged every 3-4 days after cells were fed to $90 \%$ confluence.

\section{In vitro evaluation of cytotoxic activity}

Cytotoxicity was determined using CV staining method, which is considered one of the simplest, quickest and most reliable methods to determine the viability of adherent cells especially for the assessment of the interactions between anticancer agents (Saotome et al. 1989; Sliwka et al. 2016).

Briefly, a $100 \mu \mathrm{l}$ of culture media containing $5 \times 10^{3}$ cells was added into each well of a flat-bottomed 96-well plate and incubated for $24 \mathrm{~h}$ at $37^{\circ} \mathrm{C}$ in a $\mathrm{CO}_{2}$ incubator in order for cells attachment. After that, cells were treated with $100 \mu$ of the complete medium containing either six concentrations of TOPO-Sol in a range of $(1.56-50 \mu \mathrm{M})$ or six concentrations of TOPO-Sol in a range $(1.56-50 \mu \mathrm{M})$ in combination with a fixed concentration of carvacrol $(166 \mu \mathrm{M})$, and incubated for $24 \mathrm{~h}$ at $37^{\circ} \mathrm{C}$ in a $\mathrm{CO}_{2}$ incubator. Then, the culture media was discarded, followed by washing the wells carefully with a $100 \mu \mathrm{l}$ of PBS. Then $50 \mu \mathrm{l}$ of $0.1 \% \mathrm{CV}$ stain was added and incubated in the dark hood for 10 minutes. After the incubation time, CV stain was removed and the wells were washed with tap water using the immersion technique and were left to dry. Finally, $100 \mu \mathrm{l}$ of $1 \%$ SDS was added to each well followed by manually plate agitation for 10 minutes. The absorbance (A) was read at $570 \mathrm{~nm}$ using a microplate reader (BioTek, Synergy HT microplate reader, USA). Wells containing negative and positive controls included culture media without cells (blank) and culture media containing cells without treatment (control) respectively. Half maximal inhibitory concentration $\left(\mathrm{IC}_{50}\right)$ values were determined experimentally for each treatment. Experiments for each sample were done in triplicate.

The percentages of growth inhibition were calculated by the following equation:

$$
\text { Growth Inhibition }(\%)=\left(1-\frac{(\text { A of treated cell }-\mathrm{A} \text { of blank })}{(\text { A of positve control }-\mathrm{A} \text { of blank })}\right) \times 100
$$

\section{Assessment of combination therapy sy- nergism}

The growth inhibition percentages resulted from the CV assay were inserted into CompuSyn software (Combosyn, Paramus, NJ, USA), in order to determine the combination index values of the carvacrol/TOPO combination therapy in different cell lines based on the combination index theorem of Chou-Talalay (Chou 2010). When CI $>1$, the effect is antagonism and when $\mathrm{CI}<1$, the effect is synergism. 


\section{Assessment of TOPO cellular uptake}

Topotecan cellular accumulation was assessed in cells by using spectrofluorometer according to the method of Lei et al. (2010). Cells were plated in 24-well plates at cell density of $25 \times 10^{3}$ cells/well in DMEM supplemented medium. Twenty-four hours later, cells were incubated for additional $24 \mathrm{~h}$ with different TOPO concentrations, selected previously from the CV staining assay, in the absence or presence of a fixed concentration of carvacrol $(166 \mu \mathrm{M})$. After $24 \mathrm{~h}$ treatment, the cell medium was removed and the wells were washed with $300 \mu$ of ice-cold PBS, then $1 \mathrm{ml}$ of DMSO were added for 10 minutes in order to lyse the cells. Then, the supernatants were col- lected and centrifuged at $14,000 \mathrm{rpm}$ for 15 minutes to remove cell debris and to obtain cell lysate. The unique intense fluorescence of TOPO (Francis et al. 2015), in the supernatant was measured by a spectrofluorometer (F-2000 Fluorescence spectrophotometer, Hitachi, Japan) at excitation and emission wavelengths of $\lambda$ ex $=$ $360 \mathrm{~nm}$ and $\lambda \mathrm{em}=560 \mathrm{~nm}$, respectively to determine TOPO concentration. To adjust the background fluorescence from cellular components, different concentrations $(0.0125,0.25,0.5,1,2,4 \mu \mathrm{M})$ of TOPO were dissolved in DMSO and added to the untreated cells. Then the fluorescence intensities of supernatants were measured in order to prepare TOPO calibration curve in the presence of untreated cell lysates.

$$
\text { TOPO cellular accumulation ratio }=\frac{\text { TOPO concentration in cells treated with carvacrol/TOPO combination therapy }}{\text { TOPO concentration in cells treated with only TOPO }}
$$

\section{Cell morphology characterization under light microscope}

To evaluate the morphological changes of the treated MCF7, HCT116, HeLa, HepG2, A549 and SKOV3 cell lines, cells were plated at a density of $5 \times 10^{3}$ cells per well into each well of the flat-bottomed 96-well plate and were incubated overnight in a $\mathrm{CO}_{2}$ incubator at $37^{\circ} \mathrm{C}$. After cells attachment, $100 \mu \mathrm{l}$ of drug concentrations selected earlier based on the $\mathrm{IC}_{50}$ values of TOPO solutions measured by the $\mathrm{CV}$ assay, were added after discarding the old medium and were incubated for $24 \mathrm{~h}$ at the same previous conditions in the absence or presence of $(166 \mu \mathrm{M})$ carvacrol. Finally, cell morphology was evaluated by light microscope (TH4-200, Olympus optical Co-Ltd, Japan) after staining the cells with $0.02 \%$ CB R-250, according to the method of Alkhatib et al. (2017).

\section{Morphological assessment of apoptotic cells using fluorescent microscope}

The DNA fragmentation and nuclear abnormalities of the treated cells undergoing apoptosis were detected by using the DAPI stain. Cells were seeded at a density of $5 \times 10^{3}$ cells per $100 \mu \mathrm{l}$ of DMEM into the wells of the 96 wellplates. Then cells were treated with the different TOPO concentrations $\left(\mathrm{IC}_{50}\right)$ selected according to the results measured by the CV assay, in the absence or presence of $(166 \mu \mathrm{M})$ carvacrol. Following incubation for $24 \mathrm{~h}$ at $37^{\circ} \mathrm{C}$ in a $\mathrm{CO}_{2}$ incubator, cell morphology of the DAPI stained cells was assessed by a fluorescent microscope with blue filter at $437 \mu \mathrm{m}$ (Leica CRT6000, Germany) according to the method of Alkhatib et al. (2018).

\section{Statistical analysis}

Statistical analysis was implemented using MegaStat Excel (version 10.3, Butler University, Indianapolis, IN). All data were expressed as mean \pm standard deviation (SD) for triplicate measurements. Independent $t$-test was used for the comparison between two independent groups and one- way analysis of variance (ANOVA) followed by Tukey's test for post hoc analyses were used for multiple comparisons. Statistical differences were considered significant, highly significant and very highly significant when $0.01 \leq$ $P<0.05,0.001 \leq P<0.01$ and $P<0.001$, respectively.

\section{Results}

\section{Effect of carvacrol on TOPO cytotoxici- ty in different cancer cell lines}

The cytotoxicity of TOPO in the absence or the presence of $(166 \mu \mathrm{M})$ carvacrol in HeLa, HCT116, MCF-7, HepG2, A549, and SKOV3 cancer cells were expressed as the percentages of growth-inhibiting rates (Fig. 1). The $(166 \mu \mathrm{M})$ carvacrol concentration, which is smaller than the resulted carvacrol $\mathrm{IC}_{50}$ concentration in each cell line, was chosen and unified for all cancer cells. The $\mathrm{IC}_{50} \mathrm{~s}$ of the different treatment protocols, and their combination indexes were also evaluated as presented in Table 1. Six TOPO concentrations ranged from

Table 1. Effect of carvacrol/TOPO combination therapy on the growth of different cancer cell lines and their combination indexes (CI). Data were expressed as mean $\pm \mathrm{SD}$, in triplicate.

\begin{tabular}{|c|c|c|c|}
\hline $\begin{array}{l}\text { Cancer } \\
\text { Cell Line }\end{array}$ & TOPO IC $_{50}(\mu \mathrm{M})$ & $\begin{array}{c}\text { (TOPO + carvacrol } \\
(166 \mu \mathrm{M})) \mathrm{IC}_{50}(\mu \mathrm{M})\end{array}$ & $\begin{array}{l}\text { (TOPO + carvacrol } \\
(166 \mu \mathrm{M})) \text { CI-value }\end{array}$ \\
\hline \multirow[t]{2}{*}{ HeLa } & $26.57 \pm 0.50$ & $3.45 \pm 0.31^{* * * *}$ & $1.23 \mathrm{E}-19$ \\
\hline & & & Synergism \\
\hline \multirow[t]{2}{*}{ HCT116 } & $15.88 \pm 0.08$ & $2.78 \pm 0.25^{* * * *}$ & 0.20 \\
\hline & & & Synergism \\
\hline \multirow[t]{2}{*}{ MCF-7 } & $12.65 \pm 0.05$ & $18.91 \pm 0.37^{* * * * *}$ & 9.80 \\
\hline & & & Antagonism \\
\hline \multirow[t]{2}{*}{ HepG2 } & $5.5 \pm 0.5$ & $7.35 \pm 0.31^{*}$ & 36.80 \\
\hline & & & Antagonism \\
\hline \multirow[t]{2}{*}{ SKOV3 } & $32.50 \pm 2.50$ & $48.83 \pm 1.61^{* * *}$ & 3.19 \\
\hline & & & Antagonism \\
\hline \multirow[t]{2}{*}{ A549 } & $10.63 \pm 0.32$ & $13.39 \pm 0.53^{* *}$ & 14.89 \\
\hline & & & Antagonism \\
\hline
\end{tabular}

Notes: the significant differences between TOPO $\mathrm{IC}_{50} \mathrm{~s}$ in the absence or presence of a fixed concentration of carvacrol $(166 \mu \mathrm{M}) . \mathrm{IC}_{50}$ in each cell line assessed by mesuring the $P$-values using the independent $t$-test, were classified to ${ }^{\star} P<0.05$, ** $P<0.01,{ }^{* * *} P<0.001$ and ${ }^{* * * *} P<0.0001$. 


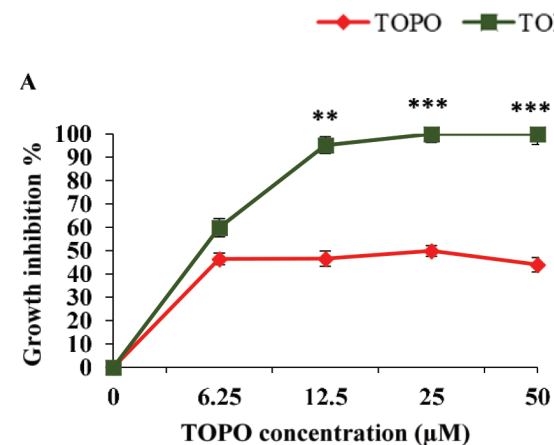

carvacrol $(166 \mu \mathrm{M})$

C

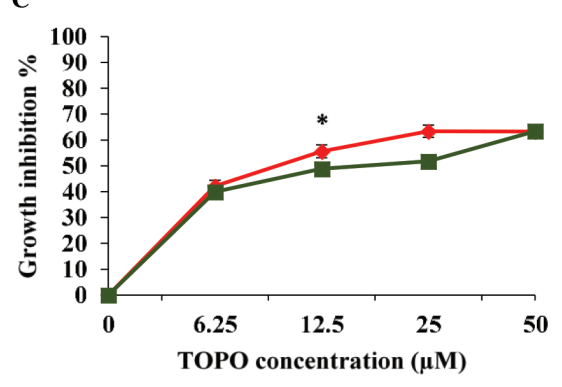

$\mathbf{E}$

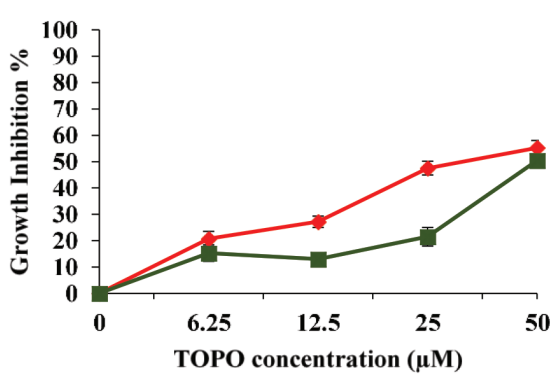

B

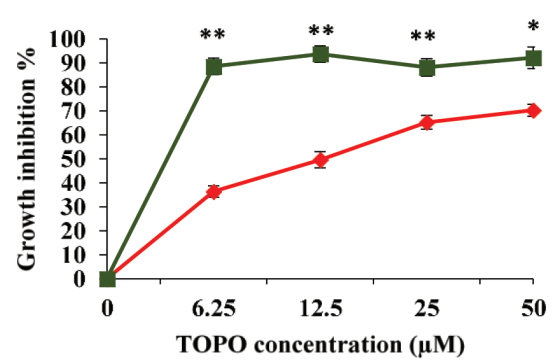

D

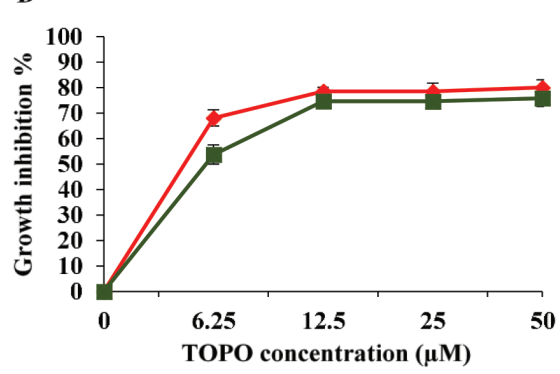

$\mathbf{F}$

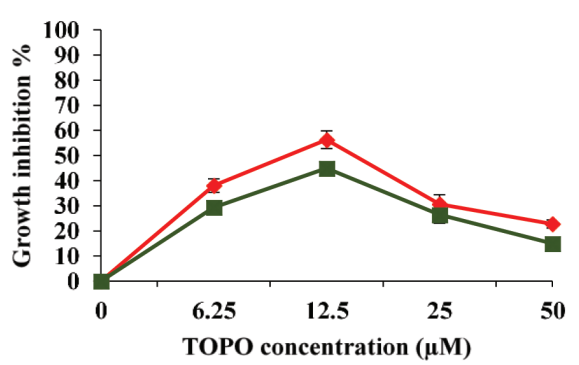

Figure 1. The curves of the growth inhibition percentages after $24 \mathrm{~h}$ treatment with different concentrations of TOPO in the absence or presence of a fixed concentration of carvacrol $(166 \mu \mathrm{M})$ ) in (A) HeLa, (B) HCT116, (C) MCF-7, (D) HepG2, (E) SKOV3 and (F) A549 cell lines. Data were expressed as mean $\pm \mathrm{SD}$ (error bars), $n=3$. The significant differences between TOPO and (TOPO + carvacrol $(166 \mu \mathrm{M}))$ combination at each time assessed by mesuring the $P$-values using the independent $t$-test, were classified to ${ }^{*} P$ $<0.05,{ }^{* *} P<0.01$ and ${ }^{* *} P<0.001$.

1.56 to $50 \mu \mathrm{M}$ were added to cells, either alone or combined with $(166 \mu \mathrm{M})$ carvacrol, then the cytotoxicity was estimated after $24 \mathrm{~h}$ by $\mathrm{CV}$ assay. The statistical comparisons between different treatment protocols at the same TOPO concentration were performed by the independent $t$-test.

Simultaneous addition of carvacrol to TOPO in cancer cells for $24 \mathrm{~h}$ was found to sensitize or inhibit TOPO growth inhibition percentage, depending on the type of the treated cancer cells. In HeLa and HCT116 cells, the growth inhibitory curves of TOPO combined with $(166 \mu \mathrm{M})$ carvacrol were significantly increased relative to the curves of TOPO given alone at

TOPO concentrations of 25 and $50 \mu \mathrm{M}(P<0.001)$ in HeLa cells and at TOPO concentrations of $6.25,12.5$ and $25 \mu \mathrm{M}(P<0.01)$ in HCT116 cells. However, the growth inhibitory curves of the combination therapy were found to be decreased in comparison with TOPO alone in MCF7, HepG2, A549, and SKOV3 cancer cells.

In terms of $\mathrm{IC}_{50}$ as illustrated in Table 1 , HeLa and HCT116 cells treated with TOPO and $(166 \mu \mathrm{M})$ carvacrol combination, were having a highly significant smaller $\mathrm{IC}_{50}$ than TOPO solution at $P$ - value $<0.0001$, which means that carvacrol addition to TOPO may enhanced its cytotoxic effect. The $\mathrm{IC}_{50}$ values were reduced by factors of 7.7 and 5.7 relative to TOPO single treatment in HeLa and HCT116 cells, respectively. Moreover, the combination indexes of cells treated with the combination treatment were less than one in both cell lines, indicating a synergistic effect between TOPO and carvacrol.

On the other hand, the addition of carvacrol to TOPO has significantly increased the $\mathrm{IC}_{50}$ values relative to TOPO single treatment in MCF-7 $(P<0.0001)$, HepG2 $(P<0.05)$, A549 $(P<0.001)$, and SKOV3 $(P<0.01)$. In other words, carvacrol addition to TOPO may reduced its cytotoxic effect as understood from their combination index values which are all larger than one, indicating antagonism.

\section{Effect of carvacrol on TOPO cellular up- take in different cancer cell lines}

The different cell lines were treated with two concentrations of TOPO $(2$ and $5 \mu \mathrm{M})$ in the absence or presence of 

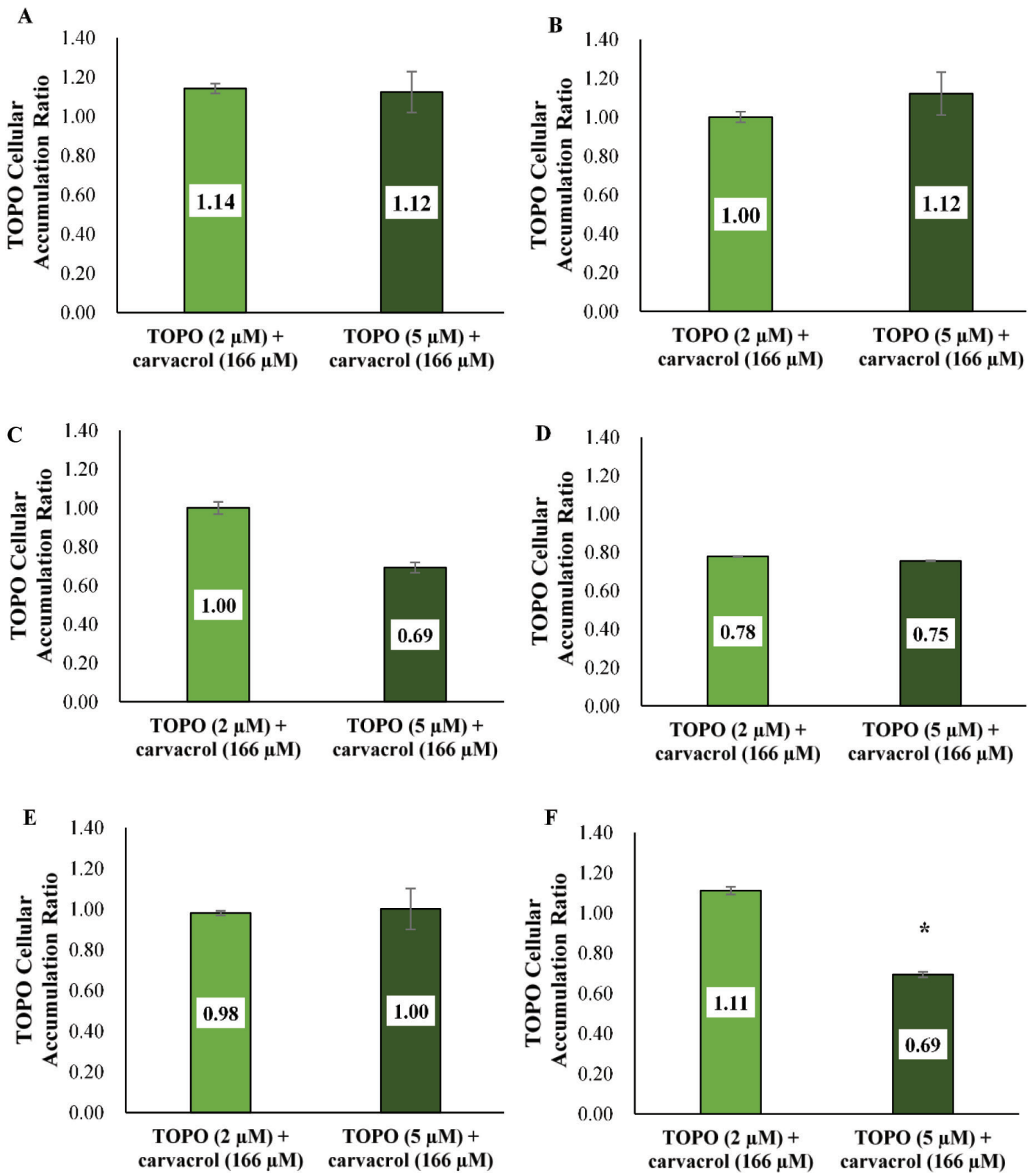

Figure 2. The effect of the $24 \mathrm{~h}$ treatment with (TOPO $(2$ or $5 \mu \mathrm{M})+$ carvacrol $(166 \mu \mathrm{M}))$ combination on TOPO cellular uptake in (A) HeLa, (B) HCT116, (C) MCF-7, (D) HepG2, (E) SKOV3 and (F) A549 cell lines. Data were expressed as mean \pm SD (error bars), $n=3$. The significant differences between the different (TOPO + carvacrol $(166 \mu \mathrm{M}))$ combinations at each time assessed by mesuring the $P$-values using the independent $t$-test, were classified to ${ }^{\star} P<0.05$.

$(166 \mu \mathrm{M})$ carvacrol. TOPO intracellular uptake concentrations in HeLa, HCT116, MCF-7, HepG2, SKOV3, and A549 cancer cells and their accumulation ratios after treatment with TOPO alone or in combination with carvacrol, were illustrated in Table 2 and Fig. 2, respectively. In HeLa and HCT116 cells, carvacrol co-administration with TOPO has increased its TOPO intracellular concentration especially when given with the higher $(5 \mu \mathrm{M})$ TOPO concentration. The accumulation ratio of TOPO was 1.12 when both cell lines were treated with $(5 \mu \mathrm{M})$ TOPO and $(166 \mu \mathrm{M})$ carvacrol combination, which means that carvacrol may enhanced TOPO cellular uptake.

In contrast to the effect of carvacrol on TOPO cellular uptake in HeLa and HCT116 cells, carvacrol caused a slight decrease in TOPO intracellular concentration when
Table 2. Effect of carvacrol/TOPO combination therapy on TOPO cellular uptake in different cancer cell lines. Data were expressed as mean $\pm \mathrm{SD}$, in triplicate.

\begin{tabular}{lcccc}
\hline Cancer $\begin{array}{c}\text { Cell } \\
\text { line }\end{array}$ & $\begin{array}{c}\text { TOPO } \\
(2 \mu \mathrm{M})\end{array}$ & $\begin{array}{c}\text { TOPO }(\mathbf{2} \boldsymbol{\mu M})+ \\
\text { carvacrol }(\mathbf{1 6 6} \boldsymbol{\mu M})\end{array}$ & $\begin{array}{c}\text { TOPO } \\
(\mathbf{5} \mu \mathrm{M})\end{array}$ & $\begin{array}{c}\text { TOPO }(5 \mu \mathrm{M})+ \\
\text { carvacrol }(\mathbf{1 6 6} \boldsymbol{\mu M})\end{array}$ \\
\hline HeLa & $0.068 \pm 0.000$ & $0.077 \pm 0.017$ & $0.077 \pm 0.017$ & $0.087 \pm 0.017$ \\
HCT116 & $0.066 \pm 0.018$ & $0.066 \pm 0.018$ & $0.086 \pm 0.018$ & $0.097 \pm 0.018$ \\
MCF-7 & $0.059 \pm 0.019$ & $0.059 \pm 0.019$ & $0.070 \pm 0.033$ & $0.049 \pm 0.019$ \\
HepG2 & $0.085 \pm 0.016$ & $0.066 \pm 0.000$ & $0.075 \pm 0.016$ & $0.057 \pm 0.016$ \\
SKOV3 & $0.055 \pm 0.017$ & $0.054 \pm 0.015$ & $0.046 \pm 0.017$ & $0.046 \pm 0.015$ \\
A549 & $0.096 \pm 0.018$ & $0.106 \pm 0.018$ & $0.138 \pm 0.018$ & $0.096 \pm 0.018 *$ \\
\hline
\end{tabular}

Notes: Significant differences between the intracellular uptake in cells treated with only TOPO and with (the same TOPO concentration + carvacrol $(166 \mu \mathrm{M}))$ combination in each cell line assessed by mesuring the $P$-values using the independent $t$-test, were significat at ${ }^{*} P<0.05$. 
carvacrol was added to $5 \mu \mathrm{M}$ TOPO in MCF-7, HepG2 and A549 cancer cells (Table 2). The decrease in TOPO intracellular concentration when $(166 \mu \mathrm{M})$ carvacrol was added to $(5 \mu \mathrm{M})$ TOPO, was more obvious relative to its effect on the lower $(2 \mu \mathrm{M})$ TOPO concentration. TOPO accumulation ratios were $0.69,0.75$ and 0.69 when MCF7, HepG2 and A549 cancer cells treated with $(5 \mu \mathrm{M})$ TOPO and $(166 \mu \mathrm{M})$ carvacrol combination, respectively. Accordingly, carvacrol may reduce TOPO cellular uptake.

\section{Cell morphology characterization under light microscope}

Cell morphologies were assessed under light microscope for HeLa, HCT116, MCF-7, HepG2, A549, and SKOV3 cancer cells. As displayed in Figs 3 and 4, the images of control (untreated) HeLa, HCT116, MCF-7, HepG2, A549, and SKOV3 cancer cells, revealed the whole cells with no evidence of segmentation or fragmentation, but when cells subjected to TOPO alone or in combination with $(166 \mu \mathrm{M})$ carvacrol, morphological changes were observed.

In all cell lines (Figs 3,4), the images of cells treated with TOPO showed a clear signs of nuclei shape changing and apoptotic characteristics such as cell enlargement with cytoplasm shrinkage, membrane blebbing (outward pulge of cytoplasmic membrane), chromatin condensation (chromatin margination without nuclear condensation), intercellular space increase and cell structure loss. Furthermore, in HeLa and HCT116 cells (Fig. 3A, B), the cell number population was decreased in TOPO treated cells relative to control, and that decrease in addition to the other apoptotic characteristics, were more dramatic in cells treated with TOPO and $(166 \mu \mathrm{M})$ carvacrol combination therapy. In contrast, the addition of $(166 \mu \mathrm{M})$ carvacrol to TOPO in MCF-7, HepG2, A549, and SKOV3 cancer cells (Fig. 4A-D), caused no change or a slight increase in cell population in comparison to cells treated with only TOPO.

\section{Morphological assessment of apoptotic cells using fluorescent Microscope}

Fluorescent nuclear staining with the cell permeable nucleic acid dye (DAPI) was used to assess alterations in nuclear morphology after treatment of HeLa, HCT116, MCF-7, HepG2, A549, and SKOV3 cancer cells with the $\mathrm{IC}_{50}$ concentrations of TOPO in absence or presence of $(166 \mu \mathrm{M})$ carvacrol and incubated for $24 \mathrm{~h}$ (Figs 5, 6). Although the nuclei of the healthy control cells of all the different cell lines were large and displayed smooth, uniform and diffused staining under the fluorescent microscope, the nuclei of treated cells showed clear changes of nuclear morphology. All the different cell lines when treated with their $\mathrm{IC}_{50}$ TOPO concentrations, which were selected based on the results of the growth inhibition curves illustrated in Fig. 1, clearly represented an early induction of apoptosis.

In HeLa and HCT116 cells (Fig. 5A, B), obvious nucleus enlargement and decrease in cell population were seen after TOPO treatment, and these apoptotic characteristics were more dramatic when carvacrol was added to TOPO. Also, in MCF-7, HepG2, A549, and SKOV3 cancer
A

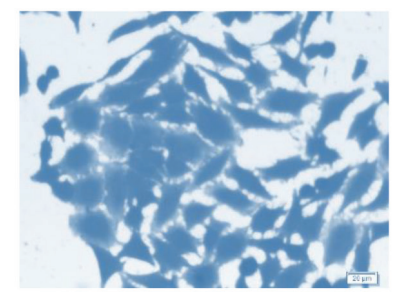

HeLa Control

B

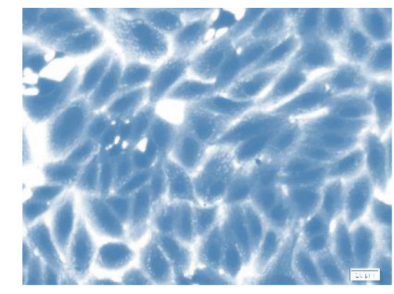

HCT116 Control

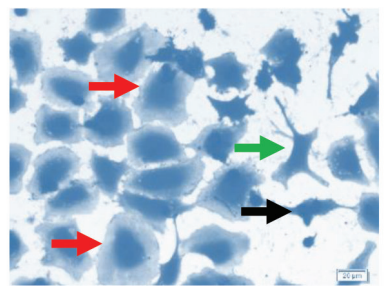

TOPO $(25 \mu \mathrm{M})$

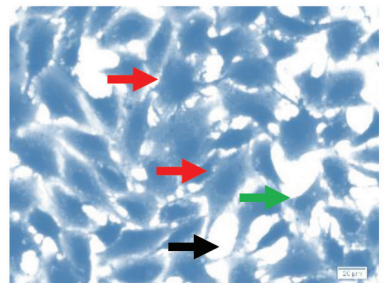

TOPO (15 $\mu \mathrm{M})$

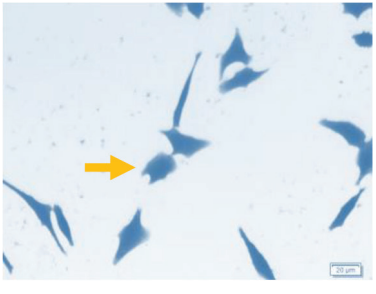

TOPO $(25 \mu \mathrm{M})+$

Carvacrol (166 $\mu \mathrm{M})$

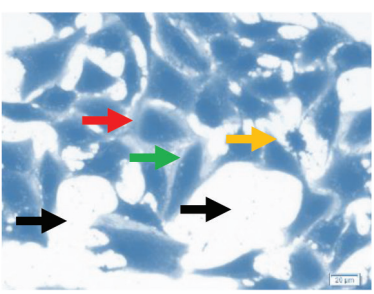

TOPO $(15 \mu \mathrm{M})+$ Carvacrol $(166 \mu \mathrm{M})$

Figure 3. Light microscopy images (Scale bar: $20 \mu \mathrm{m}$ ) of (A) HeLa and (B) HCT116 cell lines treated for $24 \mathrm{~h}$ with TOPO $\mathrm{IC}_{50}$ in the absence or presence of carvacrol $(166 \mu \mathrm{M})$. Images were magnified at $20 \times$. The red, green, orange and black arrows represented cell enlargement with cytoplasm shrinkage, membrane blebbing, apoptotic bodies and intercellular space increase, respectively. Images were taken from at least three independent experiments with similar conditions. 
A

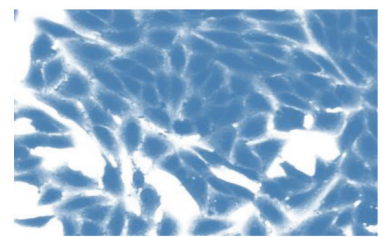

MCF-7 Control

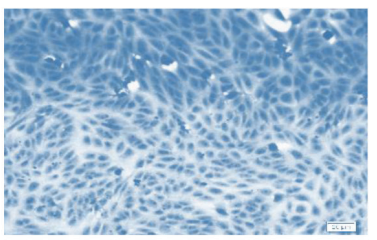

HepG2 Control

C

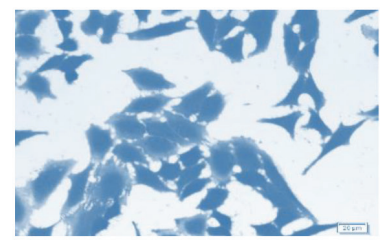

SKOV3 Control

D

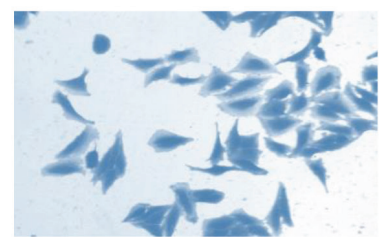

A549 Control

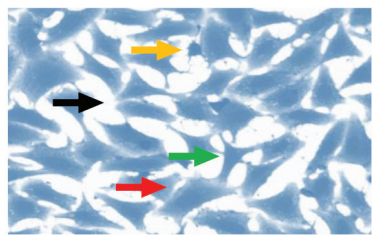

TOPO (13 $\mu \mathrm{M})$

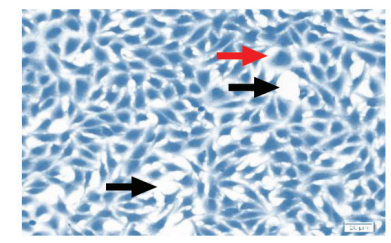

TOPO (5 $\mu \mathrm{M})$

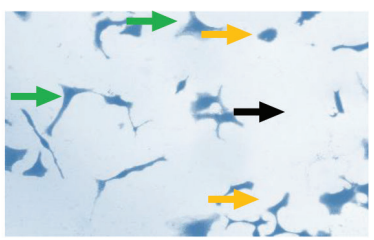

TOPO (30 $\mu \mathrm{M})$

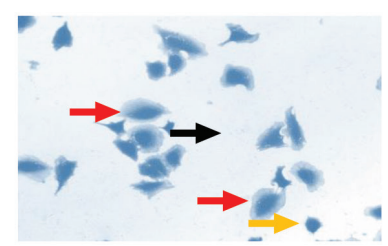

TOPO (10 $\mu \mathrm{M})$

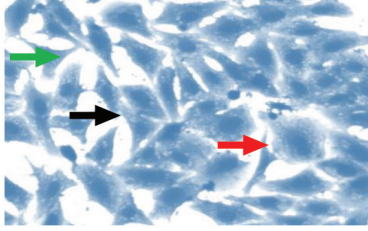

TOPO $(13 \mu \mathrm{M})+$

Carvacrol (166 $\mu \mathrm{M})$

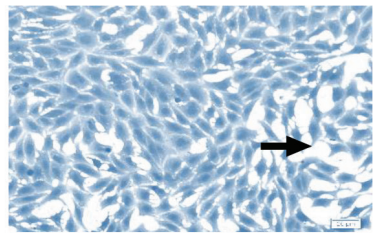

TOPO $(5 \mu \mathrm{M})+$ Carvacrol (166 $\mu \mathrm{M})$

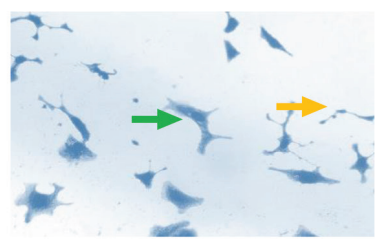

TOPO (30 $\mu \mathrm{M})+$

Carvacrol (166 $\mu \mathrm{M})$

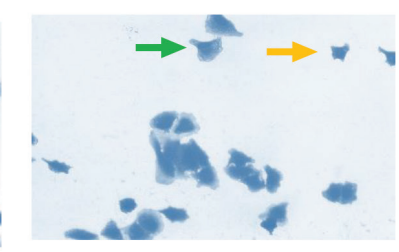

TOPO $(10 \mu M)+$

Carvacrol $(166 \mu \mathrm{M})$

Figure 4. Light microscopy images (Scale bar: $20 \mu \mathrm{m}$ ) of (A) MCF-7, (B) HepG2, (C) SKOV3 and (D) A549 cell lines treated for $24 \mathrm{~h}$ with TOPO $\mathrm{IC}_{50}$ in the absence or presence of carvacrol $(166 \mu \mathrm{M})$. Images were magnified at $20 \times$. The red, green, orange and black arrows represented cell enlargement with cytoplasm shrinkage, membrane blebbing, apoptotic bodies and intercellular space increase, respectively. Images were taken from at least three independent experiments with similar conditions.

cells (Fig. 6A-D), nuclear abnormalities and cell population decrease were observed, but when cells were treated with the TOPO and $(166 \mu \mathrm{M})$ carvacrol combination, the previous apoptotic features were diminished relative to TOPO lone treatment.

\section{Discussion}

Because treatment with TOPO alone is unlikely to be curative and is prone to resistance and severe toxicities, there is an interest in combining TOPO with natural and safer anticancer agents that has a different mechanism of cell death (Wang et al. 2012). Despite this interest, relatively few in vitro studies examining TOPO-phytochemical combinations have been performed. Therefore, in this study we combined carvacrol, which is a natural antican- cer agent, with TOPO treatment, then, we investigated the modulatory effect of it on TOPO cytotoxicity in various cancer cell lines. The possible modulatory mechanisms were assessed by examining TOPO cellular uptake and cellular morphological changes after treatment with different TOPO concentrations in the presence or absence of $(166 \mu \mathrm{M})$ carvacrol.

Carvacrol, the monoterpenoid phenolic phytochemical, has demonstrated cytotoxic effects in several human cancer cells such as cervical cancer (Potocnjak et al. 2018), colon cancer (Fan et al. 2015), breast cancer (Mari et al. 2020), hepatoma (Yin et al. 2012; Elshafie et al. 2017), ovarian cancer (Elbe et al. 2020), and non-small cell lung cancer (Koparal and Zeytinoglu 2003; Jung et al. 2018). In contrast to TOPO mechanism of action, the mechanism of carvacrol antiproliferative effect was through reactive oxygen species induced apoptosis in most of the tested 
A

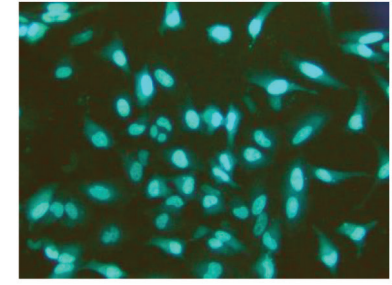

HeLa Control

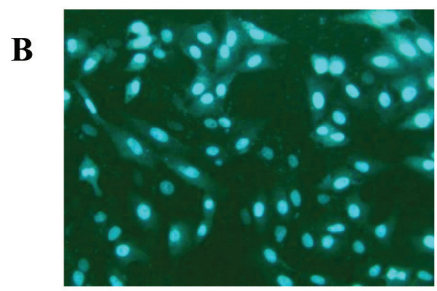

HCT116 Control

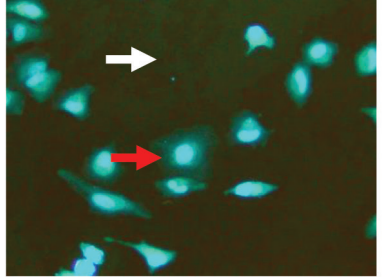

TOPO $(25 \mu \mathrm{M})$

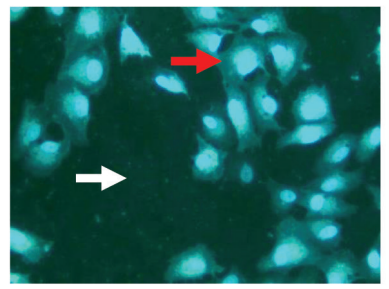

TOPO $(15 \mu \mathrm{M})$

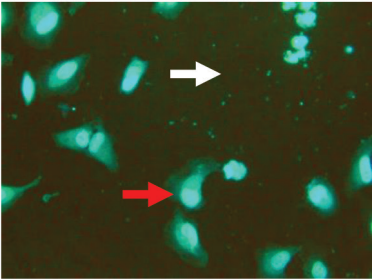

TOPO $(25 \mu \mathrm{M})+$

Carvacrol $(166 \mu \mathrm{M})$

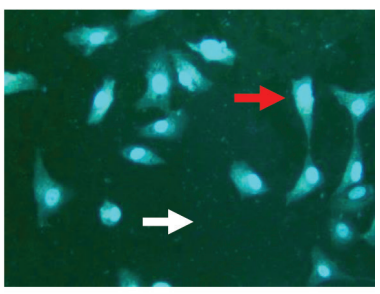

TOPO $(15 \mu \mathrm{M})+$ Carvacrol $(166 \mu \mathrm{M})$

Figure 5. Fluorescent microscopy images (Scale bar: $20 \mu \mathrm{m}$ ) of A) HeLa and B) HCT116 cell lines treated for $24 \mathrm{~h}$ with TOPO IC 50 in the absence or presence of carvacrol $(166 \mu \mathrm{M})$. Images were magnified at $20 \times$. The red, and white arrows represented nuclear enlargement or irregular shape, and intercellular space increase, respectively. Images were taken from at least three independent experiments with similar conditions.

cancer cell lines (Potocnjak et al. 2018). Therefore, in this study we studied the modulatory effect of carvacrol on TOPO cytotoxicity, cellular uptake and induced cellular morphology changes.

The results indicated that HeLa cervical cancer cells and HCT 116 colon cancer cells showed an increase in their sensitivity when treated with carvacrol/TOPO combination therapy relative to the free-TOPO. Moreover, the addition of carvacrol to TOPO caused a highly significant 7.70- and 5.71-fold decrease in the $\mathrm{IC}_{50}$ concentrations $(P$-value < 0.0001 ) relative to TOPO single treatment in HeLa and HCT116 cells, respectively. The decrease in $\mathrm{IC}_{50}$ value, indicated that the combination treatment was more cytotoxic than TOPO alone because lower TOPO dose was needed to exert $50 \%$ cell death, than the dose needed to exert the same effect in both cell lines when treated with free-TOPO. To explore the mechanism behind the previous results, light and fluorescent microscopy images were taken after $24 \mathrm{~h}$ of the TOPO-carvacrol combination treatment. The images illustrated an increase in all the apoptotic features noticed in TOPO single treatment in both types of cancer cells especially the reduced cell population (Alkhatib et al. 2020). Our findings agreed with previous studies that showed carvacrol induced apoptosis through DNA fragmentation in HeLa cells (Mehdi et al. 2011), and through mitochondrial apoptotic pathway and the MAPK and PI3K/Akt signaling pathway in HCT116 cancer cells (Fan et al. 2015).

Furthermore, our data indicated an increase in TOPO intercellular levels after the addition of carvacrol, which was in accord with the decreased TOPO $\mathrm{IC}_{50}$ concen- trations, and the increased apoptotic features exhibited earlier in treated HeLa and HCT116 cells. In fact, TOPO was proven to be a substrate of P-glycoprotein, the ATP dependent active transporter in cancer cells, and multidrug resistance associated protein 1 (MRP1) drug transporters (Tian et al. 2006), while carvacrol was proven to be an inhibitor of P-glycoprotein mediated transport in LLC-GA5-CoL150 renal cancer cell line (Yoshida et al. 2006). Accordingly, carvacrol may inhibit TOPO efflux by inhibiting P-glycoprotein drug transporter and MRP1, resulting in an increase TOPO intercellular concentration compared to cells treated with single TOPO treatment.

The cytotoxic effect resulted from an interaction between two agents is considered synergistic, either when it is greater than the expected effect from one of these agents alone or when it is equal to the cytotoxic effect resulted from one of the two single agents but at better tolerated reduced drug concentration (Ramsay et al. 2005; Chou 2010). Therefore, a synergistic interaction between TOPO and carvacrol may be concluded, due to all the previous findings and due to the calculated CI values, which were less than one, in HeLa and HCT116 cancer cells. A previous study confirmed that some herbal phytochemicals were found to inhibit P-glycoprotein and at the same time cause direct cytotoxic effect, thereby, exerting synergistic interaction with camptothecins (the parent compound of TOPO) (Bansal et al. 2009).

On the other hand, in MCF-7, HepG2, A549, and SKOV3 cancer cells, our findings exhibited a decrease in TOPO induced cellular growth inhibition percentages after the addi- 
A

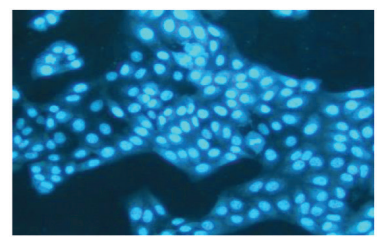

MCF-7 Control

B

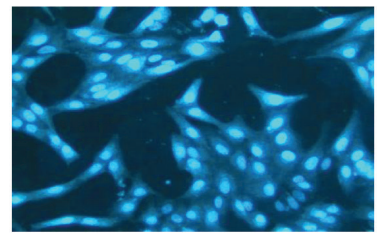

HepG2 Control

C

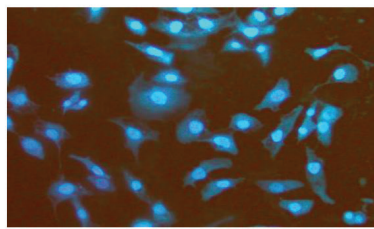

SKOV3 Control

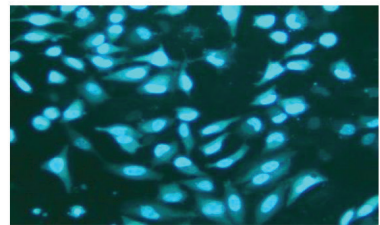

A549 Control

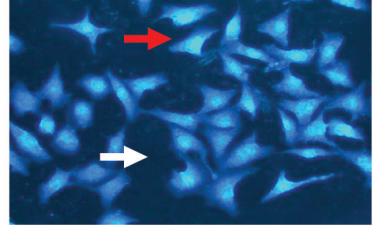

TOPO (13 $\mu \mathrm{M})$

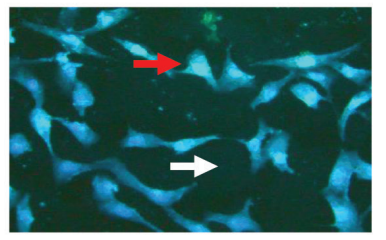

TOPO (5 $\mu \mathrm{M})$

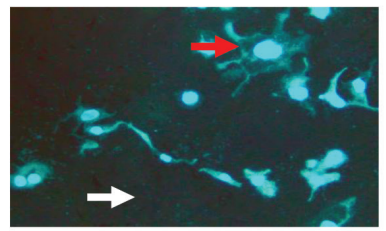

TOPO (30 $\mu \mathrm{M})$

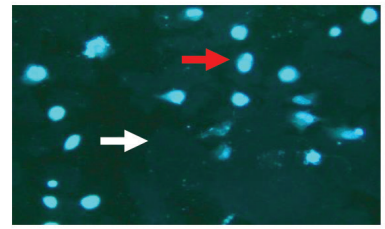

TOPO (10 $\mu \mathrm{M})$

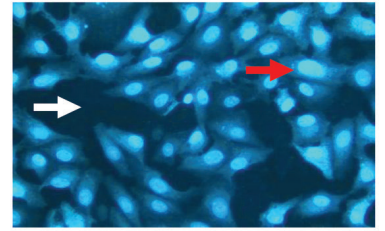

TOPO (13 $\mu \mathrm{M})+$ Carvacrol (166 $\mu \mathrm{M})$

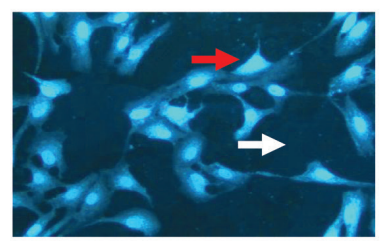

TOPO $(5 \mu \mathrm{M})+$ Carvacrol (166 $\mu \mathrm{M})$

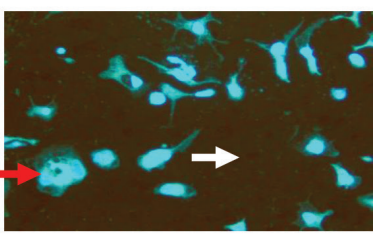

TOPO (30 $\mu \mathrm{M})+$ Carvacrol $(166 \mu \mathrm{M})$

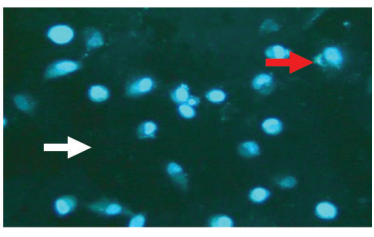

TOPO $(10 \mu \mathrm{M})+$ Carvacrol (166 $\mu \mathrm{M})$

Figure 6. Fluorescent microscopy images (Scale bar: $20 \mu \mathrm{m}$ ) of (A) MCF-7, (B) HepG2, (C) SKOV3 and (D) A549 cell lines cell lines treated for $24 \mathrm{~h}$ with TOPO IC ${ }_{50}$ in the absence or presence of carvacrol $(166 \mu \mathrm{M})$. Images were magnified at $20 \times$. The red, and white arrows represented nuclear enlargement or irregular shape, and intercellular space increase, respectively. Images were taken from at least three independent experiments with similar conditions.

tion of carvacrol in comparison with TOPO alone. Also, the $\mathrm{IC}_{50}$ concentrations were significantly increased relative to the $\mathrm{IC}_{50}$ of TOPO single treatment in the same cell line. In addition, CB R-250 and DAPI stained images illustrated no difference or slight increase in cell viability relative to cells treated with TOPO alone. These results can be explained because carvacrol may exert different types of interaction with anticancer agents depending on the treated cancer cell line and the combined anticancer drugs. For example, carvacrol was found to be cytotoxic against HeLa cancer cells but when combined with cisplatin (the DNA damaging anticancer drug) it induced resistance through apoptosis and autophagy modulation (Potocnjak et al. 2018).

Moreover, the TOPO accumulation ratios were decreased when TOPO-carvacrol treatment protocol was used, which was more significant when higher TOPO concentrations were combined with carvacrol especially in MCF-7 and A549 cancer cells. The reduced TOPO in- tercellular concentration was indicated by the decreased cytotoxic effect and the increased $\mathrm{IC}_{50}$ noticed after the addition of carvacrol to TOPO, suggesting a possible induction of TOPO efflux from the intercellular compartment through P-glycoprotein or other efflux pump, which is a quite common mechanism of resistance to chemotherapeutic agents (Ughachukwu and Unekwe 2012).

It can be concluded from the carvacrol/TOPO combination therapy protocol in MCF-7, HepG2, A549, and SKOV3 cancer cells that carvacrol exhibited an antagonistic effect when combined with TOPO, although it was proven to be cytotoxic when given alone in the previous literature (Koparal and Zeytinoglu 2003; Yin et al. 2012; Elshafie et al. 2017; Jung et al. 2018; Elbe et al. 2020; Mari et al. 2020).

These conflicting findings between the effect of carvacrol-TOPO combination on HeLa and HCT116 cells and its effect against MCF-7, HepG2, A549, and SKOV3 cancer cells can be explained because TOPO was found 
to exert different kinds of interactions with other anticancer agents, depending on the type of cancer cell line being treated (Kaufmann et al. 1996). Addtionally, some of the famous P-glycoprotein inhibitors like cyclosporine A and verapamil can induce P-glycoprotein expression in colon cancer cell line (Herzog et al. 1993). Sometimes the same phytochemical can cause an opposite effect on cytotoxicity and cellular uptake of the combined anticancer agent in the same cancer cell line depending on the treatment sequence, this happened when resveratrol (natural phytochemical) was combined with doxorubicin, the chemotherapeutic agent, either simultaneously or $24 \mathrm{~h}$ before doxorubicin in MCF-7 cancer cells (Osman et al. 2012). Therefore, carvacrol can cause a synergistic or antagonistic interaction effect with TOPO and it may inhibit or increase the expression of P-glycoprotein drug transporter, depending on the cancer cell type being examined.

\section{Conclusion}

The current study revealed that carvacrol can modulate the cytotoxic effect of TOPO either synergistically like in
HeLa and HCT116 cancer cells, or antagonistically like in MCF-7, HepG2, A549, and SKOV3 cancer cells. After the carvacrol-TOPO combination treatment, TOPO cellular uptake was either increased (HeLa and HCT116 cells) or decreased (MCF-7, HepG2, A549, and SKOV3 cells) depending in the cell type being treated. The mechanism of cell death in both types of interactions was through induction of apoptosis, but the intensity of apoptosis was in accord with the intercellular concentration of TOPO that was modulated by carvacrol. Further studies should be applied in vitro and in vivo to confirm the results of this study that showed a possible beneficial effect of carvacrol and TOPO combination in the treatment of cervical and colon cancer, but antagonistic effects were showed for the same combination in breast, liver, ovarian and lung cancer.

Also, this research calls for further studies to investigate the effect of TOPO, carvacrol and their combination on P-glycoprotein mediated resistance and hence by the TOPO intracellular accumulation and to explore the molecular mechanism of the apoptotic cell death after the carvacrol-TOPO combination therapy in various cancer cell lines.

\section{References}

Alkhatib MH, Al-Otaibi WA, Wali AN (2018) Antineoplastic activity of mitomycin $\mathrm{C}$ formulated in nanoemulsions-based essential oils on HeLa cervical cancer cells. Chemico-Biological Interactions 291: 72-80. https://doi.org/10.1016/j.cbi.2018.06.009

Alkhatib MH, Alyamani SA, Abdu F (2020) Incorporation of methotrexate into coconut oil nanoemulsion potentiates its antiproliferation activity and attenuates its oxidative stress. Drug delivery 27: 422-430. https://doi.org/10.1080/10717544.2020.1736209

Alkhatib MH, Theeban S, Backer W (2017) Antitumor activity of mixing gemcitabine with pravastatin in a microemulsion against a549 nonsmall cell lung cancer cells. International Journal of Pharma and Bio Sciences 8: 41-47. https://doi.org/10.22376/ijpbs.2017.8.2.p41-47

Armstrong DK, Spriggs D, Levin J, Poulin R, Lane S (2005) Hematologic safety and tolerability of topotecan in recurrent ovarian cancer and small cell lung cancer: an integrated analysis. Oncologist 10: 686694. https://doi.org/10.1634/theoncologist.10-9-686

Bansal S, Bajaj P, Pandey S, Tandon V (2017) Topoisomerases: Resistance versus Sensitivity, How Far We Can Go? Medicinal Research Reviews 37(2): 404-438. https://doi.org/10.1002/med.21417

Bansal T, Jaggi M, Khar RK, Talegaonkar S (2009) Emerging significance of flavonoids as P-glycoprotein inhibitors in cancer chemotherapy. Journal of Pharmacy \& Pharmaceutical Sciences 12: 46-78. https:// doi.org/10.18433/J3RC77

Bray F, Ferlay J, Soerjomataram I, Siegel RL, Torre LA, Jemal A (2018) Global cancer statistics 2018: GLOBOCAN estimates of incidence and mortality worldwide for 36 cancers in 185 countries. CA: A Cancer Journal of Clinicians 68(6): 394-424. https://doi.org/10.3322/ caac. 21492

Chou TC (2010) Drug combination studies and their synergy quantification using the Chou-Talalay method. Cancer Research 70(2): 440-446. https://doi.org/10.1158/0008-5472.CAN-09-1947
Elbe H, Yigitturk G, Cavusoglu T, Baygar T, Ozgul Onal M, Ozturk F (2020) Comparison of ultrastructural changes and the anticarcinogenic effects of thymol and carvacrol on ovarian cancer cells: which is more effective? Ultrastruct Pathol 44: 193-202. https://doi.org/10. 1080/01913123.2020.1740366

Elshafie HS, Armentano MF, Carmosino M, Bufo SA, De Feo V, Camele I (2017) Cytotoxic Activity of Origanum Vulgare L. on Hepatocellular Carcinoma cell Line HepG2 and Evaluation of its Biological Activity. Molecules 22(9): e1435. https://doi.org/10.3390/molecules22091435

Fachini-Queiroz FC, Kummer R, Estevao-Silva CF, Carvalho MD, Cunha JM, Grespan R, Bersani-Amado CA, Cuman RK (2012) Effects of Thymol and Carvacrol, Constituents of Thymus vulgaris L. Essential Oil, on the Inflammatory Response. Evidence-Based Complementary and Alternative Medicine 2012: e657026. https://doi. org/10.1155/2012/657026

Fan K, Li X, Cao Y, Qi H, Li L, Zhang Q, Sun H (2015) Carvacrol inhibits proliferation and induces apoptosis in human colon cancer cells. Anticancer Drugs 26: 813-823. https://doi.org/10.1097/ CAD.0000000000000263

Francis JH, Marr BP, Schaiquevich P, Kellick MG, Abramson DH (2015) Properties and clinical utility of topotecan fluorescence: uses for retinoblastoma. British Journal of Ophthalmology 99(10): 1320-1322. https://doi.org/10.1136/bjophthalmol-2015-306633

Herzog CE, Tsokos M, Bates SE, Fojo AT (1993) Increased mdr-1/P-glycoprotein expression after treatment of human colon carcinoma cells with P-glycoprotein antagonists. The Journal of Biological Chemistry 268: 2946-2952. https://doi.org/10.1016/S0021-9258(18)53865-5

Jung CY, Kim SY, Lee C (2018) Carvacrol Targets AXL to Inhibit Cell Proliferation and Migration in Non-small Cell Lung Cancer Cells. Anticancer Research 38: 279-286. https://doi.org/10.21873/anticanres. 12219 
Kaufmann SH, Peereboom D, Buckwalter CA, Svingen PA, Grochow LB, Donehower RC, Rowinsky EK (1996) Cytotoxic effects of topotecan combined with various anticancer agents in human cancer cell lines. Journal of the National Cancer Institute 88(11): 734-741. https://doi. org/10.1093/jnci/88.11.734

Khan I, Bahuguna A, Kumar P, Bajpai VK, Kang SC (2018) In vitro and in vivo antitumor potential of carvacrol nanoemulsion against human lung adenocarcinoma A549 cells via mitochondrial mediated apoptosis. Scientific Reports 8: e144. https://doi.org/10.1038/s41598-017-18644-9 Koparal AT, Zeytinoglu M (2003) Effects of Carvacrol on a Human NonSmall Cell Lung Cancer (NSCLC) Cell Line, A549. Cytotechnology 43: 149-154. https://doi.org/10.1023/B:CYTO.0000039917.60348.45

Lei T, Srinivasan S, Tang Y, Manchanda R, Fernandez-Fernandez A, Mcgoron AJ (2010) Targeted Delivery of Doxorubicin by PLGA Nanoparticles Increases Drug Uptake in Cancer Cell Lines. In: Herold KE, Vossoughi J, Bentley WE (Eds) $26^{\text {th }}$ Southern Biomedical Engineering conference SBEC, College Park, Maryland (USA), April 30 - May 2, 2010. Springer, Berlin, Heidelberg. https://doi. org/10.1007/978-3-642-14998-6_57

Mari A, Mani G, Nagabhishek SN, Balaraman G, Subramanian N, Mirza FB, Sundaram J, Thiruvengadam D (2020) Carvacrol Promotes Cell Cycle Arrest and Apoptosis through PI3K/AKT Signaling Pathway in MCF-7 Breast Cancer Cells. Chinese Journal of Integrative Medicine. https://doi.org/10.1007/s11655-020-3193-5

Mehdi SJ, Ahmad A, Irshad M, Manzoor N, Rizvi MMA (2011) Cytotoxic effect of carvacrol on human cervical cancer cells. Biology and Medicine 3: 307-312. https://www.probotanic.com/images/antikancerogeni_karvakrol.pdf

Newman DJ, Cragg GM (2016) Natural Products as Sources of New Drugs from 1981 to 2014. Journal of Natural Products 79: 629-661. https://doi.org/10.1021/acs.jnatprod.5b01055

O’Dwyer PJ, LaCreta FP, Haas NB, Halbherr T, Frucht H, Goosenberg E, Yao KS (1994) Clinical, pharmacokinetic and biological studies of topotecan. Cancer Chemother Pharmacol 34 Suppl: S46-52. https:// doi.org/10.1007/BF00684863

Osman AM, Bayoumi HM, Al-Harthi SE, Damanhouri ZA, Elshal MF (2012) Modulation of doxorubicin cytotoxicity by resveratrol in a human breast cancer cell line. Cancer Cell International 12: e47. https:// doi.org/10.1186/1475-2867-12-47

Potocnjak I, Gobin I, Domitrovic R (2018) Carvacrol induces cytotoxicity in human cervical cancer cells but causes cisplatin resistance: Involvement of MEK-ERK activation. Phytotherapy Research 32(6): 1090-1097. https://doi.org/10.1002/ptr.6048

Ramsay EC, Dos Santos N, Dragowska WH, Laskin JJ, Bally MB (2005) The formulation of lipid-based nanotechnologies for the delivery of fixed dose anticancer drug combinations. Current Drug Delivery 2(4): 341-351. https://doi.org/10.2174/156720105774370294
Rang HP, Dale MM (2012) Rang and Dale's pharmacology. Elsevier Churchill Livingstone, Edinburgh, 792 pp. https:/doi.org/10.1016/ B978-0-7020-3471-8.00001-9

Saotome K, Morita H, Umeda M (1989) Cytotoxicity test with simplified crystal violet staining method using microtitre plates and its application to injection drugs. Toxicol In Vitro 3: 317-321. https://doi. org/10.1016/0887-2333(89)90039-8

Sharifi-Rad M, Varoni EM, Iriti M, Martorell M, Setzer WN, Del Mar Contreras M, Salehi B, Soltani-Nejad A, Rajabi S, Tajbakhsh M, Sharifi-Rad J (2018) Carvacrol and human health: A comprehensive review. Phytotherapy Research 32: 1675-1687. https://doi.org/10.1002/ ptr.6103

Sliwka L, Wiktorska K, Suchocki P, Milczarek M, Mielczarek S, Lubelska K, Cierpial T, Lyzwa P, Kielbasinski P, Jaromin A, Flis A, Chilmonczyk Z (2016) The Comparison of MTT and CVS Assays for the Assessment of Anticancer Agent Interactions. PLoS ONE 11: e0155772. https://doi.org/10.1371/journal.pone.0155772

Tian Q, Zhang J, Chan SY, Tan TM, Duan W, Huang M, Zhu YZ, Chan E, Yu Q, Nie YQ, Ho PC, Li Q, Ng KY, Yang HY, Wei H, Bian JS, Zhou SF (2006) Topotecan is a substrate for multidrug resistance associated protein 4. Current Drug Metabolism 7: 105-118. https://doi. org/10.2174/138920006774832550

Ughachukwu P, Unekwe P (2012) Efflux pump-mediated resistance in chemotherapy. Annals of Medical and Health Sciences Research 2: 191-198. https://doi.org/10.4103/2141-9248.105671

Wang H, Khor TO, Shu L, Su ZY, Fuentes F, Lee JH, Kong AN (2012) Plants vs. cancer: a review on natural phytochemicals in preventing and treating cancers and their druggability. Anti-Cancer Agents in Medicinal Chemistry 12: 1281-1305. https://doi. org/10.2174/187152012803833026

Yin QH, Yan FX, Zu XY, Wu YH, Wu XP, Liao MC, Deng SW, Yin LL, Zhuang YZ (2012) Anti-proliferative and pro-apoptotic effect of carvacrol on human hepatocellular carcinoma cell line HepG-2. Cytotechnology 64: 43-51. https://doi.org/10.1007/s10616-0119389-y

Yoshida N, Koizumi M, Adachi I, Kawakami J (2006) Inhibition of P-glycoprotein-mediated transport by terpenoids contained in herbal medicines and natural products. Food and Chemical Toxicology 44: 2033-2039. https://doi.org/10.1016/j.fct.2006.07.003

Zotti M, Colaianna M, Morgese MG, Tucci P, Schiavone S, Avato P, Trabace L (2013) Carvacrol: from ancient flavoring to neuromodulatory agent. Molecules 18: 6161-6172. https://doi.org/10.3390/molecules 18066161 